Portland State University

PDXScholar

1975

\title{
Shaping of Marital Interaction: a Clinical-Research Approach
}

Cynthia Luders Clay

Portland State University

Follow this and additional works at: https://pdxscholar.library.pdx.edu/open_access_etds

Part of the Clinical Psychology Commons

Let us know how access to this document benefits you.

\section{Recommended Citation}

Clay, Cynthia Luders, "Shaping of Marital Interaction: a Clinical-Research Approach" (1975). Dissertations and Theses. Paper 2191.

https://doi.org/10.15760/etd.2188

This Thesis is brought to you for free and open access. It has been accepted for inclusion in Dissertations and Theses by an authorized administrator of PDXScholar. Please contact us if we can make this document more accessible: pdxscholar@pdx.edu. 
AN ABSTRACI OF THE THESIS OF Cynthia Iuders clay for the Master of Science in Psychology presented July 21, 1975.

Title: Shaping of Marital Interaction: A ClinicalResearch Approach.

APPROVED BX THE NENBERS OF THE THESIS CONMITTTEE:
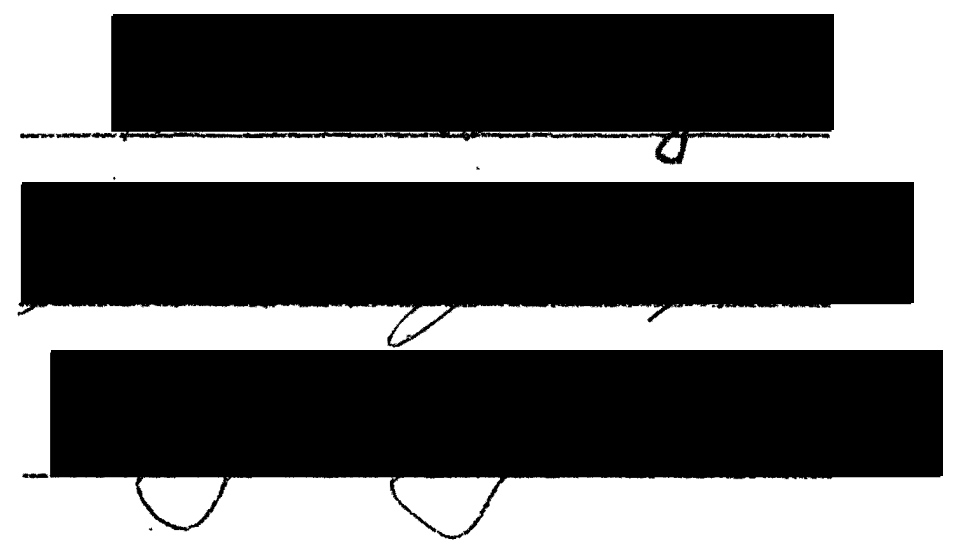

In the last ten years, a number or behavioral approaches to marital therapy have been developed and. applied to married couples. Intervention techniques have included selective reinforcement, extinction; modeljng, aversive consequences, and contingency contadoting. Wine presert study investigated the use of the bug-in-the-ear (BIIE) instrument as an aid in shaping marital interaction. The BIIE jas becn applied in several child behavior modification programs, but no applications in maited therapy have been reported.

This study utilized the clinical-research approach with four narried units (US). In the course of ten shaping 
sessions, procedures were used to modify the U's interactions. On the basis of theoretical deductions and empirical data, seven target behaviors were selected and criteria were established. The target behaviors were Attending, Talk, Question, Interruption, Disagreement, Agreement, and Both Talk. During the intervention sessions any of these behaviors which did not meet criteria during baseline were shaped until the response rate of all subjects met the criterion levels.

A Mann-Whitney U Test showed significant ircreases in Talk and Attending for the husband of Unit I and increases in all target behaviors for the husband of Units II, III, and IV. Similar increases in desirable behaviors occured for the wives. All significant increases were at the $p<.05$ level. Some target behaviors did not charge significantly, while others showed increasing trends. Interrater reliability estimates ranged from $r=.99$ to $r=.82$ for two trained and experienced observers.

The use of the BITE has been demonstrated and is considered clinically feasible. Since the $N$ of this study was small and since the raters evaluating progress were knowledgeable and indeed involved in the hypotheses under investigation, caution must be exercised in the evaluation of the data. The necessity for evaluation of specific further research issues is discussed. 
SHAPING OF MARITAI INTERACTION:

A CIINICAI-RESEARCH APPROACH

by

CYNTHIA LUDERS CLAY

A thesis submitted in partial fulfillment of the requirements for the degree of:

MAS TER OF SCIENCE

in

PSYCHOLOGY

Portland State University 1975 
TO THE OFFICE OF GRADUATE STUDIES AND RESEARCH:

The members of the Committee approve the thes is of Cynthia Luders Clay presented July 21, 1975.
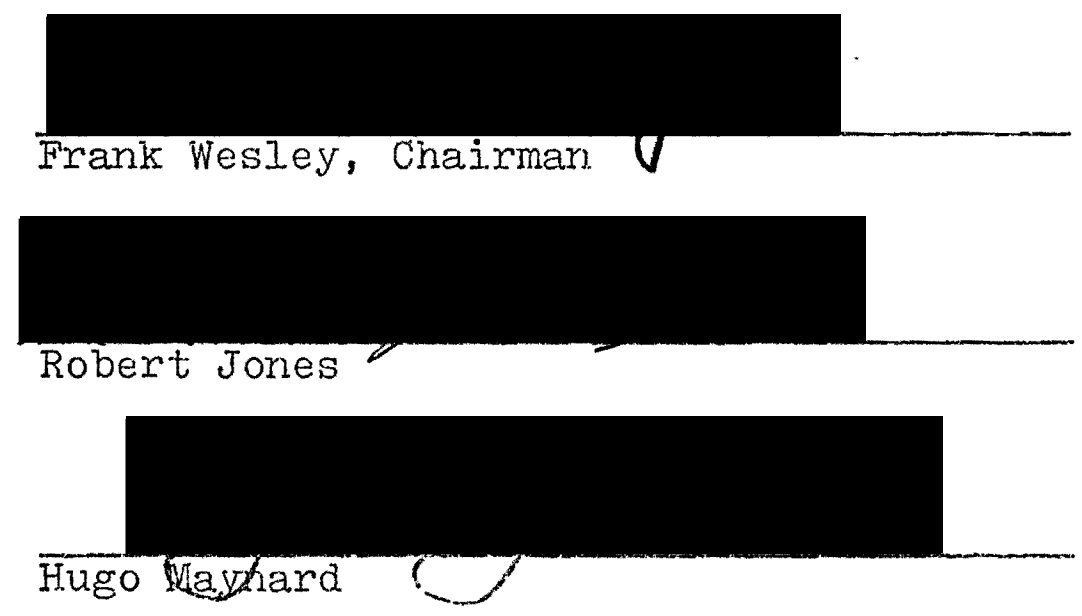

\section{A.PPROVED:}
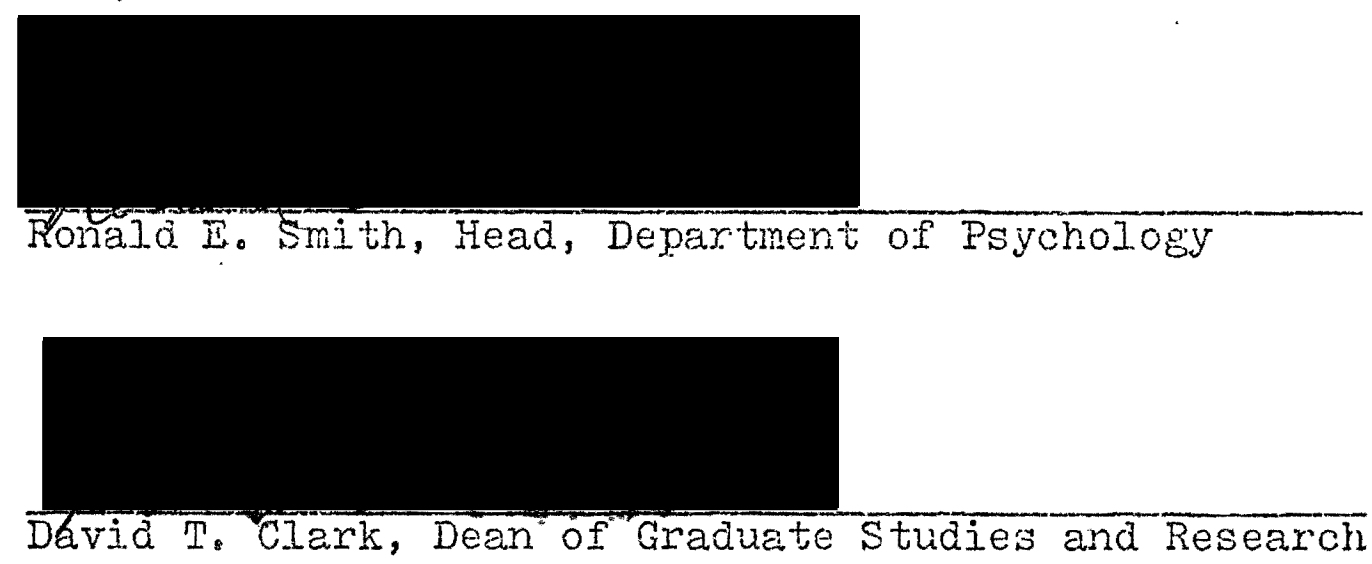

July 21, 1975 


\section{ACKNOWLEDGNENTS}

I would like to express my appreciation to all of those in the Department of Psychology who assisted me in the development and completion of this project: Frank Wesley, who generously contributed the limited time he had in Portland, and gave valuable suggestions and encouragement; to Bob Jones and Hugo Maynard, the other members of my committee, for contributing their time, patience, and advice; to Ron Smith and Roger Jennings, who helped with the arrangements for the program; and to Jim Paulson, for his statistical expertise and advise.

Last but not least, I would like to express my gratitude to Otto Arnoscht who contributed to the development of this program and who acted as the co-therapist in this study. 
TABLE OF CONTENTS

PAGE

ACKNOWLEDGMENTS . . . . . . . . . . . .

IIST OF TABLES. . . . . . . . . . . .

vii

CHAPTER

I INTRODUCTION. . . . . . . . . . 1

Research Hypotheses . . . . . 4

II A REVIEW OF THE IITERATURE. . . . . .

Operant Approaches to

Marital Therapy . . . . . 5

Uses of the Bug-in-the-ear. . . . 18

III NETHOD. . . . . . . . . . . 22

Subjects. . . ...... 22

Physical Setting. . . . . . 23

Procedure ......... 23

Pre-therapy Interviews

Intake Interview

Clay-Arnoscht Behavioral

Interview Form

Clay-Arnoscht Narital Inventory

Use of the Intake Data

Baseline Sessions

Standard Situation A

Standard Situation B

Standard Situation. $C$

Assessment 
Use of the Baseline

Data

Intervention Sessions

Subsession $A$

Subsession $B$

Subsession C

Post-treatment Sessions

Instrumentatior .........

Design. . ......... 35

IV RESUITS .............. 36

Individual Results. . . . . . 36

Unit I

Unit II

Unit III

Unit IV

Consolidated Results. ......

43

$\mathrm{V}$ DISCUSSION

Evaluation of the

Hypotheses. . . . . . 4 46

Iimitations of the Study. ..... 48

Issues for Further

Research. . . . ..... 49

Program Development:

and Conclusion. . . . . . 50

REFERENCES. . . . . . . . . . . . 51

APPENDICES. . . . . . . . . . . . . . 60

I AGREENENT TO PARTICIPATION

IN RESEARCH . . . . . . . . 61

II CLAY-ARNOSCHT BEHAVIORAL INTERVIEW. . . 64 
II CIAY-ARNOSCHT MARITAI INVENTORY . . . 66

IV STANDARD INSTRUCTIONS . . . . . . 69

V BEHAVIORAI CODING GUIDE . . . . . . 71

VI CRITERION IEVELS. . . . . . . . 75

VII SHAPING PROCEDURE . . . . . . . . 77 


\section{IIST OF TABIES}

TABIE

PAGE

I. Target Behavior Rates for Unit I. . . . 38

II Target Behavior Rates for Unit II . . . 40

II Target Behavior Rates for Unit III. . .. 42

IV Target Behavior Rates for Unit IV . . . 44 


\section{CHAPTER I}

\section{INTRODUCTION}

- Since 1890, the proportion of couples seeking divorce in the United States has approximately doubled every thirty years; currently, one marriage in three ends in divorce (Christensen, 1964). Many have attempted to determine the causes of divorce. Terman (1957) suggested that couples resort to divorce not only out of marital dissatisfaction but also due to the presence or absence of religious scruples. EJIis and Harper, on the other hand, placed the blame on the complex and rapidly changing American society, stating that it would be strange indeed "to find that most. people today were living in a state of effortless marital bIiss" (ElIis \& Harper, 1961, p. 17).

Whatever the causes, the effects of marital dissatisfaction are frightful. Twenty-eight percent of all murder victims are killed by members of their own families (Federal Bureau of Investigation, 1968). Twenty percent of all poljce officers killed and $40 \%$ of those injured in the line of duty received their injuries while attempting to intervene in family disputes (Bard, 1969). Of those women obtaining divorces, $40 \%$ in the lower socio-economic class and $20 \%$ in the middle socio-economic class cited physical 
abuse as the major reason for seeking divorce (Steinmetz \& Strauss, 1971).

Not all of those remaining married are satisfied with their marriages. There is a steady decline in general marital satisfaction in both middle- and upper-class couples during the first ten years of marriage (Feldman, 1971). At least one couple in seven describes themselves as "unhappy" (Bradburn \& Caplovitz, 1965). While normal couples are confronted with conflict about once a week, distressed couples are faced with conflict at least once a day (Birchler, Weiss, \& Wampler, 1972). These conflicts are not only more frequent, they are more aversive (Vincent, $1972,1974)$ 。

Interest in and concern about the relationships of husbands and wives has existed for a long time, yet only in the last few decades has a separate profession focusing on the treatment of married couples developed (01son, 1970). Marital clinics made their debut on the American scene in the early 1930's. Since that time, research on marital therapy has proceeded "with a great amount of vigor but without a sufficient amount of rigor" (01son, 1970). Most of the research to date has focused on clinical practices and techniques illustrated by case studies. A variety of dynamic approaches have been described. These include Collaborative Matiral Therapy (Martin \& Bird, 1953), Concurrent Marital Therapy (Greene \& Solomon, 1963), 
Group Therapy (Hendersen, 1965), Conjugal Therapy (E1y, Guerney, \& Stovr, 1973), and Conjoint Marital Therapy (Satir, 1969). While these approaches could prove to be widely applicable, few have attempted to apply them to a sufficiently large population of couples in an adequately controlled manner to establish sound data.

Recently, a number of operant approaches have been reported. Most have had the goal of increasing reinforcing interactions between husband and wife. A variety of intervention techniques have been employed, including contingency contracting (Stuart, 1969; Turner, 1972; Knox, 1972; Patterson, Weiss, \& Hops, 1974), modeling (Iiberman, 1970; Patterson, Weiss, \& Hops, 1974), systematic desensitization (Lazarus, 1968), selective reinforcement (Liberman, 1970), shaping marital interaction (Iiberman, 1970; Patterson, Weiss, \& Hops, 1974), and aversive consequences (Goldstein \& Francis, 1969). These techniques and conceptualizations have for the most part been illustrated by case studies, however several sound experimental studies have been published.

One strategy of research which has been suggested is the clinical-research approach. The model for this approach begins with a case study, followed by replicated case stuaies, then a simple group-comparison study, and finally factorial studies to investigate the various parameters of the technique. In this manner, the techniques 
can be constantly tested and modified (Bergin \& Strupp, 1972)。

The present study involves the second stage of the clinical-research approach; replicated case studies which in turn influence the technique under development.

\section{RESEARCH HYPOTHESES}

The basic purpose of this study is to demonstrate the use of the bug-in-the-ear (BITE) in shaping marital interaction. The first and basic hypothesis, therefore, is that the BITE can be used in marital shaping, and that it is clinically feasible as a shaping instrument. It is further hypothesized that the BITE can be used in efficiently shaping marital interaction, without any statement about the efficiency relative to any other method of shaping marital interaction. Thirdly, it is hypothesized that in the course of a ten-session shaping program, selected target behaviors will change significantly in the desired (shaped) direction. This will be shown by a significant change in the rates of target behaviors from three baseline assessment sessions (BSIs) to three post-treatment assessment sessions (PTAs). 


\section{CHAPTER II}

\section{A. REVIEW OF THE IITERATURE}

The basic assumption of a behavioral approach is that behavior is learned and is controlled by environmental events. The operant approach emphasizes the concept that behavior is controlled by its consequences (Skinner, 1938). Cross-cultural research (Mead, 1939, 1949; Stephens, 1957; Mace \& Mace, 1960) suggests that cultural, social, and psychological learning variables play an important role in determining marital behavior. Knox (1972) stated:

Marital behavior rarely occurs independent of its consequences. Rather the outcome of a behavior will often increase or decrease the probability that a behavior will occur.. A wife who thanks her husband for calling to say he will be delayed in getting home increases the probability that he will call when he is late again (p. 4).

In the last decade a number of behavioral approaches to marj.tal therapy have been reported; a discussion of these follows.

\section{OPERANT APPROACHES TO MARITAI THERAPY}

Stuart (1968, 1969) delineated three assumptions of the operant-interpersonal approach concerning the characteristics of marital interaction: (a) the pattern of interaction between spouses is the most rewarding of all 
the alternatives in terms of rewards and costs; (b) most marital partners expect a reciprocal relationship with their spouse; and (c) modifying an unsuccessful marriage requires development of the spouses' power to mediate rewards for each other. The goal of such an approach is to construct a situation in which the frequency and the intensity of mutual reinforcement is increased.

Stuart's program consists of four steps. First, the marital unit (U) is trained in the logic of the approach, which is accomplished by setting forth two premises: (a) the impressions formed by one spouse about the other are based on the partner's behavior, and (b) the only way that change can occur is if both spouses take the initiative for changing their own behaviors. The second step involves asking each spouse to list three molecular behaviors which he or she would like the other to increase in frequency. The third step requires transcription of the three wishes of each spouse into headings on a behavioral checklist, which is posted in a convenient location in the U's home so that each spouse can record the frequency with which the other performs the target behaviors. Finally, a series of exchanges of target behaviors is arranged such that each spouse is compensated for changes in a manner which is socially reinforcing to the individual. In marriages where social reinforcement is dispensed at an equitable rate, or one in which reciprocity is present, exchanges of behaviors 
are effective. In marriages where such reciprocity is essentially absent, a token economy has proven effective. Stuart (1968) applied this program to five couples who sought treatment as a last-ditch effort to work out solutions to problems of long standing. In all five cases, the wives requested an increase in conversation and the husbands desired an increase in sexual activity. Baseline rates were 0 and .3 on a weekly basis for sexual intercourse and .25 to 1.25 hours per day for conversation. The U was trained such that wives received tokens for engaging in sexual activities with their husbands and husbands received tokens from their wives for engaging in conversation. Following 10 weeks of treatment, the rates increased to 2 to 4 times per week for sexual intercourse and 3 to 5 hours a day for conversation. All of the Us reported increased satisfaction in and commitment to their marriages after therapy.

Goldstein and Francis (1969) and Goldstein (1971) presented a different approach to marital therapy. They trained wives to modify specific behaviors of their husbands. In the first study Goldstein and Francis (1969) trained five graduate student wives to increase or extinguish a particular behavior. They were trained to behavior pinpointing, recording, selective reinforcement, and punishment. After three weeks, a significant change in the desired direction was reported for all of the husbands. In 
a replication of this study, Goldstein (1971) trained ten wives and again significant changes in the husbands' behaviors were reported.

Liberman (1970) described four case studies, three of which were married Us. He taught them to modify each others behaviors by using reinforcement and modeling in the context of ongoing interpersonal interactions. Liberman's approach is based on Reese's behavioral model for learning (Reese, 1966). Essentially this approach includes shaping the desired behavior, structuring a favorable situation for eliciting the behavior by providing cues for the appropriate behavior, and removing cues for incompatible and inappropriate behaviors. Selective reinforcement is applied at the same time.

Iiberman personally modeled desirable behaviors during therapy sessions and demonstrated how these behaviors should be reinforced. He points out that the therapist (T) "is an effective reinforcer and model for the patients to the extent that the patients value him and hold him in high regard and warm esteem." Assuming that social reinforcement (verbal and nonverbal means of giving attention and recognition) represents the most important source of motivation for human behavior (Ferster, 1963; Skinner, 1953; Bandura \& Walters, 1963), Liberman instructs the Us to reward desirable behaviors by giving the spouse attention when desirable responses are emitted. He also instructed them to ignore 
undesirable behaviors. Within 5 to 15 sessions, improvement was sufficient to terminate therapy. Follow-up contacts indicated that the behaviors taught in treatment were maintained in the home environment.

Turner (1972) designed the Positive Narriage Management Program in which lectures on the principles of behavior modification, reading assignments, personal instruction and assistance in behavior charting, pinpointing behavioral problems, and shaping are applied to groups of married Us. In six sessions, the Us are taught to establish contingency contracts. The evaluation of the program was based on the responses of the Us on questionnaires. Most expressed satisfaction with the program and a willingness to recommend it to friends. There were no behavioral assessments of improvement.

One of the reading assignments used by Turner is Knox's Marriage Happiness (1972). Knox suggests using pinpointing, behavioral charting, establishment of environmental contingencies, and some classical conditioning procedures to achieve desirable changes in marital interaction and satisfaction. Knox initiates intervention with training in pinpointing and charting of specific behaviors. Each spouse should state which behavior they want the other to increase, decrease, modify, or terminate. The spouses are then trained to keep accurate records of the frequency and the circumstances under which the target 
behaviors occur. Charts are helpful not only in deciding which contingencies should be established, but to evaluate the changes over time. Finally, the stimulus variables which influence behavior are manipulated by the $\underline{T}$ or the $\underline{U}$. When possible, the Us are seen together by the $\underline{\text { I for two }}$ purposes: (a) to encourage the marital partners to work together to resolve their difficulties and to view the marital problems as "unit" problems; and (b) to obviate the notion that one spouse is sick and is thus responsible for all of the marital problems. This approach was illustrated by twelve case studies which showed various degrees of success.

Eisler, Hersen, and Agras (1973) described a program which tested the effects of videotape and instructional feedback on nonverbal interaction. Twelve Us were assigned to one of four conditions: videotape feedback, irrelevant television programming, videotape feedback with focused instructions, and focused instructions alone. The dependent variables were looking and smiling. The results indicated that the first condition slightly increased the Us." nonverbal interaction; the fourth condition was more effective in increasing looking; and the third condition, albeit not superior to the fourth, raised the level of smiling.

A social learning formulation (Bandura \& Walters, 1963; Bandura, 1969) of marital interaction emphasizes the 
control which is exerted on a subject's behavior by social agents. According to this formulation, human behavior is maintained by social reinforcement, extinguished by the lack of social reinforcement, learned by imitating social agents, and used to obtain social reinforcements. Social learning theory incorporates operant and classical conditioning phenomena as well as modeling. In this conceptualization, a well-adjusted marriage is one in which the partners exchange positive reinforcements and only rarely utilize escape paradigms to coerce the partner into desirable behaviors. Partner A may desire partner $B$ to do behavior $X$ while partner $B$ may desire partner $A$ to do behavior $Y$. A positive reinforcement (reciprocal) paradigm would be followed if partner $A$ did $Y$ and partner $B$ reciprocated by doing $X$. An aversive or coercive paradigm would involve partner $A$ doing, $\bar{Y}$ (anything but $Y$ ) as long as partner $B$ does $\bar{X}$ (anything but $X$ ). Partner A's change from $\bar{Y}$ must be preceeded by partner $B^{\prime} s$ change to $X$, and vice versa. In effect, no change can take place. Another aversive paradigm would be used by producing $N$, a noxious stimulus. In order to kring about a change from $\bar{X}$ to $X$ in partner $B$, partner $A$ may introduce $N$ and apply $N$ until partner $B$ changes from $\bar{X}$ to $X$. Then $N$ will be stopped and the escape paradigm will be completed. Social learning theorists suggest that maladapted Us utilize these aversive paradigms rather than positive control of each other's behavior. In 
a representative statement of this formulation, Weiss,

Hops, and Patterson stated:

We assume that marital conflict is the result of faulty behavior change operations (Patterson \& Hops, 1972), and that the partners attempt to bring about immediate change in one another largely through aversive control. Their problem is to either accelerate or decelerate some behavioral rate in the other, but because prior training stressed coercive or aversive control the partners readily shape one another in the singular use of these techniques. Over time the partners learn to terminate the aversive manding behavior of the other person by change, but the process is based upon a negative reinforcement paradigm. The aversive manding behavior is strengthened by the behavior of the other which turns off the manding, thus increasing. the probability that a comparable form of aversive manding will occur in the future (1973).

Aversive control measures usually meet with initial success which reinforces their use. With time, however, the aversive stimuli need to be intensified to achieve the same effect. It is often in the late stage of such an escalation of aversiveness that the $\underline{U}$ seeks therapy.

A social learning approach to marital interaction is in some ways distinguished from a communications-oriented approach since key factors under scrutiny are the partner's social reinforcements of one another, not the accuracy of perceptions or the content of messages. In many ways, however, there are overlapping areas: the communication of an accurate perception may be reinforcing; certain speech content may be reinforcing. Therefore the social learning theorymoriented therapist is also interested in content of verbal messages。 
Prominent proponents of the social learning approach to marital interaction are the members of the Patterson group at the Oregon Research Institute. In the late 1960's this group focused on family processes and investjgated such issues as conflict in marriages, parameters of marital satisfaction, and methods of intervention.

It was not difficult to foresee the complexities involved in the task of altering marital interaction. Changing the behavior of children in the home (Wahler, Winkle, Peterson, \& Morrison, 1965) or in the classroom (Walker \& Buckley, 1973) was a breeze in comparison. After all, in these settings the parent or the teacher holds most of the key contingencies which control the behavior of the child (Patterson, Weiss, \& Hops, 1974). A parent whose child throws a tantrum can place the child in time-out, spank him, or ignore the tantrum behavior. The inequities in the parent-child relationship make for ease in intervention. On the other hand, the marriage relationship is basically an equal relationship in which both individuals hold relatively equal shares of the contingencies (Azrin, Master, \& Jones, 1973; Stuart, 1968, 1969)。 Thus any intervention with Us in severe conflict requires simultaneous changes in contingencies for both partners (Patterson, Weiss, \& Hops, 1974).

An important concept resulting from early investigations is coercive interaction. Coercion seems to be the 
major characteristic of troubled marriages, whereas reciprocity seems to be characteristic of well-adjusted Us (Patterson \& Hops, 1972; Patterson \& Reid, 1970; Reid, 1967; Weiss, Hops, \& Patterson, 1973; Patterson \& Cobb, 1971). In describing coercion, Patterson and Hops stated:

Both persons provide aversive stimuli which control the behavior of the other... it is assumed that most marriages are characterized by such a process since it becomes necessary for each member of the dyad to alter the accumulating aversiveness of rather trivial behaviors in their spouse. Conflict occurs when one party does not comply with the other's implicit or explicit demands for immediate changes in his behavior (1972).

They point to the outcome and the mechanisms which rope a U into such behavior patterns:

The negative reinforcement resulting from the termination of the aversive stimuli serves to strengthen the behavior of both parties. Following such an interchange there is an increase in the probability that a comparable form of interaction will continue in the future (1972).

Birchler, Weiss, and Wampler (1972) reported that distressed couples have approximately three times as many conflicts as non-distressed couples. In this context, coercion arises when a request is not complied with and repeated requests are more likely to be accompanied by aversive stimuli. Once a partner introduces an aversive stimulus the other is likely to reciprocate in kind. Thus, both members quickly become involved in aversive interaction. Distressed Us not only report higher mean rates of aversive consequences in the home than non-distressed Us, they are more likely to be significantly more aversive in 
their interchanges in a laboratory setting (Vincent, 1972). Intensity of such interaction escalates over time, as was suggested in the theoretical model (Patterson \& Cobb, 1971). The concomitants of this interaction are predictable: distressed Us have fewer conversations with one another, have reduced rates of sexual activity, have lower ratings on the Locke-Wallace (Locke \& Wallace, 1959), and share fewer recreational activities (Weiss, Hops, \& Patterson, 1973).

Numerous investigators have attempted to discover the determinents of marital happiness and satisfaction (Cone, 1967; Hawkins, 1967; Hicks \& Platt, 1970; Orden \& Bradburn, 1968; Tharp, 1963). Wills, Patterson, and Weiss (1974) examined marital satisfaction by having both spouses record the other's behaviors. For 14 consecutive days, each spouse recorded the other's pleasurable and displeasurable behaviors, as well as an overall rating of satisfaction for each day. The results indicated that husbands and wives were more heavily influenced by displeasurable behaviors in rating overall satisfaction. While the husband's ratings were more influenced by behaviors involving the maintainance of social and economic status of the $\underline{U}$, wives placed greater importance on behaviors with emotional significance between the partners. The hypothesis that external events would influence these ratings was not confirmed. Weiss, Hops, and Patterson (1973) suggested that the ultimate 
stability of a marriage depends on the problem solving techniques used to deal with displeasurable behaviors.

The marital intervention program developed by the group at the Oregon Research Institute focuses on three areas: (a) the exchange of affectionate behaviors between the marital partners; (b) the problem solving techniques used by the dyad; and (c) the behavior change attempts towards one another.

A standard interview is followed which explores conflicts in the major areas of marital living including money management, background differences, sex and affection. The interviewer rates distress during the interview and a baseline session is conducted. The couple is instructed to attempt to solve two major and two minor areas of conflict. Two sessions of 10 minute duration are conducted in this manner. These sessions are videotaped and coded in accordance with the MICS - the Marital Interaction Coding System (Hops, Patterson, \& Weiss, 1972). This is followed by six training sessions of 1 to $1 \frac{1}{2}$ hours duration each. Video-feedback is used, and the $\underline{U}$ is taught not to be aversive in behavior change requests and to be specific in defining problem behaviors. Weiss, Hops, and Patterson point out that co-therapists should be used for this procedure:

The kinds of communication skills lacking in couples are best modeled and trained in the sessions with the co-therapists. By modeling 
adequate information gathering ("I had a difficult day, what was yours like?") the partners can see the necessity for making specific information available to one another before undertaking remediation for the neeay spouse (1973).

By the second session of the treatment program negotiation skills necessary for quid pro quo interchanges are introduced. This approach has been discussed elsewhere (Stuart, 1969; Homme, Csanzi, Gonzales, \& Rechs, 1970; Lederer \& Jackson, 1968; Tsoi-Hoshmand, 1975). The Us are taught to think in terms of behavioral changes each can make in return for changes in the partner. The problem areas discussed by the couple during the initial interview are used as targets for contracts. The husband and wife agree on specific consequences for violations of the contracts as well as the specific behavioral changes each will make.

The MICS is used to assess the interaction of each couple. The system, devised by Hops, Patterson, and Weiss (1972), includes both verbal and nonverbal behaviors which are grouped according to five categories: verbal problem solving, verbal problem description, aversive verbalizations, aversive nonverbal behaviors, and positive nonverbal behaviors. The MICS allows the Is to evaluate the changes which occur during the teaching of negotiation skills and after they are taught. Additional information is attained by having the Us report pleasurable and displeasurable 
spouse behaviors.

In the first study to test this intervention program, Hops, Patterson, and Weiss (1972) trained five Us. The results indicated that all of the subjects increased compromise statements and reduced counterproductive behavior rates. In all five cases, the wives decreased the number of complaints and criticisms by the end of the program while the husbands slightly increased the number of their criticisms. The number of pleasures reported increased significantly; there was no change in the number of displeasures reported. In the second study of this program, Weiss, Patterson, and Hops (1973), all measures recorded on the MICS significantly changed in the desired direction for all five Us. Problem solving increased as did positive verbal and nonverbal behaviors; negative verbal and nonverbal behaviors and problem description decreased in rate. Four of the five Us reported greater marital satisfaction.

II. USES OF THE BUG-IN-THE-EAR

The bug-in-the-ear (BITE) instrument has been applied in a number of child modification programs. Most have been concerned with teaching mothers to develop more effective control behaviors to use with their children. The instrument was first reported in the literature by Welsh (1966) who described it as a highly efficient method of parental counseling. 
Hanf (1968, 1969) and Hanf and Kling (1974) used the BITE to teach mothers methods of effective control of their children's behaviors "during those daily occasions when and where adult control is required" (Hanf, 1969). Mothers were trained to produce desirable child behaviors by the systematic use of social reinforcement for desirable behaviors and "time out" and spanking for undesirable behaviors. The Ts observed from behind one-way mirrors and recorded the mother-child interaction in the therapy room. When the mother used appropriate controlling behaviors she was verbally reinforced by the $\underline{\underline{T}}$ through the BITE. Krapfl, Bry, and Nawas (1968) used the BITE to modify mother's behaviors in two case studies. In both cases the mother's behaviors had served to maintain the child's inappropriate behaviors. The mother-child interaction was observed through a one-way mirror, and the mothers (who wore the BITE) were instructed on when and how to reinforce the child's desirable behaviors as well as when and how to punish the child's inappropriate behaviors.

The authors noted that the BIIE has several advantages over the more traditional method of administering instructions to the subject. They stated that the BITE allows the I to immediately reinforce the subjects' appropriate behaviors; it allows the $\underline{\underline{T}}$ to immediately correct the subjects' inappropriate behaviors; it 
provides an opportunity for the subject to observe the consequences of her appropriate behaviors on the child, giving her immediate feedback; it obviates the possibility of the subject's misinterpretation or misapplication of the instructions; and, it allows the Is to shape the subjects in a short and fixed period of time. Krapfl, Bry, and Nawas conclude:

It is our feeling. . that one session with the bug-in-the-ear might be worth many sessions of instructions. . . It makes possible actual demonstrations which are carried out in an environment which approximates real life encounters. Finally, and perhaps most important, it utilizes the principles of operant conditioning to train parents rather than relying on more traditional instruction methods (1968).

Stumphauzer (1973) suggested that the BITE technique was much preferable to having a $I$ enter the therapy room to make suggestions or to administer reinforcements for the subjects' appropriate behaviors. The BITE "permits direct, immediate communication from supervisor to trainee without any disruption of the on-going therapy" (Stumphauzer, 1973, p. 799).

A unique use of the BITE was reported by Clement (1969). He treated problem children with social matrix therapy, inviting the child and his friends to come to the laboratory and to play. All of the children, including the child whose behavior was the focus of the study, were given the BITE on a rotating basis and acted as the therapist for a limited perjod of time. Clement found 
that the BITE was quite effective in producing the desired behavior changes. 
CHAPTER III

METHOD

\section{SUBJECTS}

Five Us voluntarily participated in this study. AII had heard about the program from the author or the author's colleagues. Demographic data concerning the 10 individials involved will be presented.

The subjects ranged in age from 23 to 37 , with a mean age of 28. Two were high school graduates, the rest some college education ranging from 1 and $1 \frac{1}{2}$ years to a Masters degree. Two of the subjects did not work, two were fulltime students, and the rest were employed in a variety of professions. All major sections of the United States were represented in the subject population. Seven of the subjects were from middle class families, two were from lower class families, and one subject was from an upper class family. Eight of the subjects were Caucasians, one was Afro-American, and one was an American Indian.

The Us had been married from 2 years, 2 months, to $9 \frac{1}{2}$ years, with a mean duration of 6 years. Their annual incomes, based on the previous year's returns, ranged from $\$ 9,000$ to $\$ 17,500$, with a mean income of $\$ 14,300$ per year. Only two of the five Us had children. 
One of the Us had to drop out of the program after two sessions due to too many time commitments.

\section{PHYSICAI SETTING}

The shaping program was executed in a therapy room and an observation room. The rooms were connected by an one-way mirror and an intercom. The therapy room contained a table placed against the mirror and two chairs which were located in front of the table and facing it and each other at 90 degree angles. A microphone for sound transmission to the observation room was placed on the table directly in front of the subject's seating area. The subjects faced each other during interaction in such a manner that the Is could observe gaze direction and facial expressions from the observation room. During the intervention sessions the therapy room was equipped with an earphone which was connected to a microphone in the observation room.

\section{PROCEDURE}

\section{Pre-Therapy Interviews}

Intake Interviews. All of the Us who volunteered their participation in the program were contacted by phone in order to schedule the intake interview. The goals for this session were: (a) for the Ts to delineate the nature and the goals of the program; (b) for the Is to discuss and 
deal with any expectations, goals, and/or possible misconceptions which the Us had relative to the program; and (c) to obtain mutual consent from both members of the $U$ to participate in and adhere to the demands of the program.

The Us were advised that the program was experimental. in nature, thus it was necessary to utilize strict controls in the program. The Ts promised to provide detailed feedback on the U's communication behaviors and to provide training in the use of these behaviors towards an improvement of the marital interaction in return for the U's participation. The subjects were further advised that for the purposes of assessment and record-keeping all sessions would be taped. They were assured that such recordings and all clinical material would remain confidential and would not be released to anyone in a form which might make the. subjects identifiable. The Us were also assured that the program did not contain any secret procedures, deceptions, or manipulations designed to induce stress. In return, the Us were asked to be available during the eight-week duration of the program at the appointed times and to complete all of the behavioral and written assignments. Finaliy the subjects were advised of their right to discontinue participation at any time, to request any information about the procedures at any time, and to receive honest answers.

After the Is described the above issues, the subjects 
were encouraged to ask any questions and/or reservations they had about the program. Any points needing additional information and clarification were discussed to ensure understanding of the program. When the procedures of the program appeared to be clear to the subjects, the Agreement of Participation in Research (see Appendix I) was introduced. The subjects were requested to read the form and to sign if they chose to participate.

Clay-Arnoscht Behavioral Interview Form (CABIF). To elicit specific information about the U's interaction, the partners were separated and each was inteviewed by the same-sex co-therapist. The interviews were taped.

The CABIF was adapted from Hanf (1968) who utilized a similar behavioral interview guide with parents of behavior-problem children. Items which were relevant to only mothers and children were deleted and those items which were appropriate for married couples were added. Problem areas suggested by Knox (1972), Steinberg and Beier (1972), and Brammer and Shostrom (1968) were included. For each of the problem areas specified in the CABIF (see Appendix II), the co-therapist asked a standard series of questions. The subjects were asked to describe a typical interaction pattern for each problem area. They were asked to describe to initial responses of both, what the specific outcomes of these situations were, and whether or not the individual subject felt the situation 
to be a problem.

The Is took brief notes during the interviews, recording brief descriptions of the subjects report and denoted areas which the subjects felt,were problems. The Is also recorded their judgements as to whether the areas seemed to be problematic based on the subject's description.

Clay Arnoscht Marital Inventory (CAMI). This inventory was closely fashioned after certain items contained in the Marital Pre-Counseling Inventory (Stuart \& Stuart, Behavior Change Systems, 1972). The Marital Pre-Counseling Inventory was considered to be a userul tool but too cumbersome for subjects who were volunteering their time.

The Us were carefully instructed on how to complete the CAMI (see Appendix III). Each spouse was given one copy to complete at home, and they were told to fill out the forms individually and not to consult with the other spouse. The Ts gave explicit examples of desirable responses orally and in writing on the forms.

Uses of the Intake Data. The main purpose of the intake interview, the CABIF, and the CAMI was to find issues relevant to each $\underline{U}$. The material was grouped into three response types: problem areas which both partners agreed were not problems in the marriage, problem areas which one partner felt presented a problem, and problem areas which both partners felt were problems in the 
marriage,

The problem areas were used as discussion topics during the sessions. They were arranged in a hierarchy based on the subject's evaluation of the sensitivity of the topic and on the I's clinical judgement as to the emotionality of the topic. Discussion topics which were not particularly sensitive or emotional in nature were discussed during the first sessions. Those which were not particularly sensitive were discussed after intervention procedures had been initiated and positive interaction behaviors had been shaped.

\section{Baseline Sessions}

The next three sessions served as baselines. The Us were given standard instructions (see Appendix IV) and a discussion topic for each session. The Is observed the US through a one-way mirror. Each baseline session was divided into three 10 minute sections. The $\underline{T}$ entered the therapy room to administer the instructions for each session.

Standard Situation A (SSA). The husband was instructed to talk about how he felt about the discussion topic for 10 minutes. The wife was told to show the husband that she understood his feelings, encouraged him to tell them to her, and to "take in" what he said. She could ask some questions to better understand what he said, but she was not to argue, disagree, or introduce new topics. The $\underline{U}$ 
was told to begin when they were cued from the observation room.

Standard Situation B (SSB). After the completion of SSA, the U was told to reverse roles. The wife was to tell her husband her feelings on the topic, and the husband was to show her that he understood her feelings, encouraged her to tell them to him, and to "take in" what she said. He could ask questions to clarify what she said, but was not to argue, disagree, or introduce new topics.

Standard Situation $\underline{C}$ (SSC). The U was told to discuss the topic equally, both giving ideas and agreeing on a course of action to deal more effectively with the problem area.

Assessment. The interaction between the Us in the baseline sessions and the intervention sessions was assessed according to the Behavioral Coding Guide (see Appendix V). This coding system contains seven behavioral categories, including Talk, Both Talk, Attending, Disagreement, Agreement, Question, and Interruption. The first three measures are duration measures and the last four are frequency measures.

The Behavior Coding Guide was adapted from coding systems developed by Hanf (1968) and Hops, Patterson, and Weiss (1972)。 The duration measures were adapted from Hanf's method of assessing such behaviors. The discrete frequency measures were adapted from Hops, Patterson, and 
Weiss。 The categories which correspond to measures included in the present study are Agree, Assent, Attention, Disagree, Interrupt, and Question.

Unfortunately, very few studies provide normative data on the interaction of normal or satisfied Us. Hanf's data were not directly applicable because they depicted mother-child interactions. The Oregon Research Institute has not published raw data on their assessments according to the NICS, but report their data in terms of five categories. However, some studies have been useful in constructing criteria levels. For example, Greenspoon (1955, 1962) found that subjects perceive certain attending behaviors as reinforcing. Stuart (1968) suggested that an equality in dispensing reinforcements between two marital partners is necessary for a reciprocal relationship. Ferreira and Winter (1965) demonstrated that a certain number of interruptions and "both talk" are necessary for an animated interaction. Kendon (1967) found that people seek feedback from others by attaining eye contact.

Thus, the criteria for the behaviors in the Behavior Coding Guide (see Appendix VI) are somewhat speculative, and future studies will be aimed at getting some normative data. For the present study, the criteria specified will be used to assess excesses and deficiencies in behavior rates.

Use of the Baseline Data. The baseline data were 
assessed and analyzed in terms of excesses and deficiencies. During the intervention sessions, the behaviors were shaped in the following order: deficient Talk, deficient Attending, deficient Agreement, excessive Disagreements, excessive Interruptions, excessive Questions, excessive Talk, and excessive Both Talk。

\section{Intervention Sessions (TRT)}

With the exception of the first intervention session (TRT 1), each TRT was divided into three subsessions: assessment of target behavior, (b) direct shaping of target behavior with the $\underline{T}$, and (c) shaping of target behavior with the BITE.

TRT 1 was altered in order to accommodate feedback of the baseline data. The data were shown to the subjects in graph form, showing the mean rates of each behavior during each standard session. Each subject was given feedback by the same-sex I. The graphs included criterion rates for each behavior as well as rates which were excessive or deficient. Each behavior was defined and the desirable direction of change in rate was indicated. For example, if the subject's Attending was below criterion, the rate was pointed out along with the rate of Attending which was acceptable. Behaviors which met criterion were praised. The other TRTs included a short assessment session which lasted five minutes in place of the feedback session. 
Subsession A (Assessment). During this subsession, the rate of the target behavior which had been shaped during the previous TRT was assessed. Criteria were set at $40 \%$ of the criteria rate used during baseline. The instructions for this subsession were those used in either SSA or SSB, depending on the target behavior. For example, if the husband's Attending was the target behavior, the instructions for SSB were given. The husband had to perform Attending for at least 61 seconds in order to meet criterion. If the target behavior met criterion, the spouse's target behavior was shaped during the remainder of the session; if not, it remained the target behavior for the rest of the session.

Following the 5 minute period, the spouse whose behavior was the target remained in the therapy room and the other spouse was seated in the waiting area.

Subsession B (Direct Shaping). Direct shaping was always done by the same-sex $I$ who followed a three step procedure (see Appendix VII). First, a favorable cognitive set was introduced. This was accomplished by presenting the rationale for the behavior and the reasons which make it desirable to increase or decrease the present rate of the target behavior.

The next step in shaping the target behavior was to model the behavior for the subject. The I modeled a partner who displayed a high rate of the target behavior 
while the subject talked. After a few minutes, the roles were reversed. The subject role-played a partner displaying a high rate of the target behavior while the $\underline{T}$ talked. When the target behavior was displayed, the I immediately reinforced the subject. This interaction continued until the subject maintained a high rate of the target behavior. The BITE was then presented to the subject along with instructions on proper wear and adjustment. Subsession $\mathrm{C}$ (Shaping with the BITE). The I brought the other spouse into the therapy room for the final 10 minutes of the TRT session. The I introduced the discussion topic during the interview. The instructions for SSA or SSB were given and the subject wearing the BITE was bugged by the I who had shaped the behavior.

When the target behavior was emitted by the subject the I immediately verbally reinforced the response. If the target behavior was not emitted for longer than 1 minute, it was prompted by the $\underline{\underline{T}}$ and reinforced when the subject complied. After the behavior was emitted at a steady and desirable rate, the $\underline{\underline{T}}$ changed to a VR3 schedule of reinforcement. After 10 minutes, the subject was reinforced for his performance.

Post-Treatment Sessions

When all of the target behaviors of both partners had been shaped to criteria, the final phase of the program was 
initiated. This involved three sessions employing the baseline procedures to determine the effect of the intervention.

\section{INSTRUNENTATION}

The bug-in-the-ear instrument, offered commercially by behavioral instrumentation supply companies, consists of a transmitter console with a microphone and a small hearing. aid-like receiver which fits behind the subject's ear. The transmitter utilizes an antenna (usually placed along the top of the wall in the therapy room) to transmit a frequency modulated signal to the receiver, the modulation being received from the microphone circuit.

Since such a unit was financially beyond the means of the author, a low-cost substitute was improvised. The method of radio frequency transmission was discarded, and a wired earphone was used instead. This earphone was connected to a variable wire-wound resister which was placed on the table next to the subject. The subject was told that he could adjust the knob on the variable resistor for pleasing audio level. The resistor in turn was connected to the output stage (monitor plug) of a portable cassette recorder. When "record" was engaged on the recorder, the modulation received through the microphone was transmitted through the wire to the earphone. Automatic recording level (a common feature on current portable cassette 
recorder models) keeps the I's voice fairly constant in level and prevents overmodulation or painful "windpops". Since the other spouse was aware that the BITE was being placed in the subjects ear, it seems that the presence of the wire did not present any additional distraction. In her studies with mothers and children, Hanf utilized an FM transmitter unit in order to keep the child from becoming aware of the BITE and to give the mother the ability to move about the room with the child and still maintain contact with the Is. Both concerns did not exist in this program because the other subject was aware of the BITE and the subjects did not move around the therapy room. 


\section{DESIGN}

This program was evaluated on the basis of the data derived from the three pre- and the three post-treatment assessments。 Post-treatment data was inspected to see if the set criterion levels had been met. To assess significance of change from pre- to post-treatment assessment, a Mann-Whitney U Test was employed for each target behavior rate and each subject under each interaction condition. Tape recordings of the interactions were rescored by the co-therapist in order to yield an estimate of inter-rater reliability of the assessments of the two raters.

Each marital U is seen as an individual case in the framework of this study, and changes in the behaviors will therefore be reviewed for each couple. Some rough indicators will be summed across couples, such as total number of behaviors which changed significantly. 
CHAPTER IV

RESULTS

Since this was a multiple case study and the individual changes of each marital $\underline{U}$ are of interest, the results of the four couples will be discussed individually.

In each case the subjects' target behaviors had been in excess or below the criteria during BSI. Behaviors were shaped in one condition and generalization of changes to other conditions was hypothesized.

Talk Ratio (see Appendix IX) was used to assess the reciprocity of the duration of talk between the spouses during BSI and PTA. It was expected that this ratio would increase for all couples from BSI to PTA.

The Mann-Whitney U Test was utilized to assess the differences in rate between the target behaviors in BSI and the same behaviors in PTA.

\section{INDIVIDUAI RESUITS}

Unit I

This couple was apparently the most distressed of all the marital Us involved in this program. The couple had heard about the program shortly after its inception and desired to participate. Baseline data reflect the extremely disturbed state of this marriage. 
The target behaviors for both the husband and the wife were Talk and Attending. Due to restrictions in the amount of time which the $\underline{U}$ could spend during PTA, SSC was the only condition where these behaviors were assessed. The husband's Attending was shaped to increase in duration. The increase in the behavior was significant $(p<.05)$. His Talk was shaped to decrease slightly in duration, however the rate did not change.

The wife's Talk was reinforced during the intervention sessions to increase the duration, and the difference following intervention was significant in the desired direction $(p<.05)$. Her Attending was also shaped to increase in rate and the difference suggested a trend $(p<.1)$.

The Talk Ratio increased from .00 during BSI to .41 during PTA.

The only target behavior which consistently met criteria during all PTA.s was the husband's Talk. The wife's Talk met crition on only. one of the PTAs. Neither the husband's nor the wife's Attending met criteria during any of the PTAs (see Table I),

Unit II

The husband's target behaviors were Question, Agreement, and Talk, all of which had an operant level below criteria. Question was assessed under SSA, SSB, and SSC, and increased significantly under only SSC $(p<.05)$. There 
TABLE I

TARGET BEHAVIOR RATES FOR UNIT I

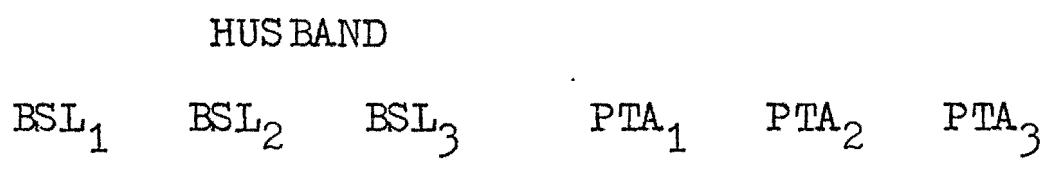

$\underline{\mathrm{SSC}}$

ATIENDING

11

$\varnothing$

90

$90 \quad 103$

TALK

234

160

139

$167 \quad 225$

156

WIFE

$\begin{array}{llllll}\mathrm{BSI}_{1} & \mathrm{BSI}_{2} & \mathrm{BSI}_{3} & \mathrm{PTA}_{1} & \mathrm{PTA}_{2} & \mathrm{PTA}_{3}\end{array}$

SSC

ATTENDING

$4 \quad 10$

26

14

73

90

TALK

$\varnothing \quad \varnothing$

$\varnothing$

121

62

41 
was an increasing trend in $\operatorname{SSB}(p<.1)$, the condition under which it was shaped; Agreement was assessed under SSB and SSC; the frequency increased significantly under SSB $(p<.05)$ and showed an increasing trend under SSC $(p<.1)$. Talk was assessed during SSB where it increased significantly $(p<.05)$.

The wife's two target behaviors functioned at deficient rates. Her Agreement increased significantly under SSA $(p<.05)$, but showed no change under SSC. Talk was assessed under SSA, and showed a significant increase $(\mathrm{p}<.05)$.

The Talk Ratio increased from .89 during BSI to .99 during PTA。

The target behaviors which met criteria during all of the PTAS were the husband's Question under SSC and the wife's Talk under SSA. The only behavior which did not meet criteria under any of the PTAS was the wife's Agreement during SSA (see Table II).

Unit III

The husband's target behaviors were Agreement, Attending, and Disagreement. The first two behaviors functioned at deficit rates and the third was in excess of the criterion level. The wife had two target behaviors: Agreement and Disagreement. The first was below criteria and the second was in excess of criteria, and thus targets. of the husband's target behaviors only Agreement 
TABLE II

TARGET BEHAVIORS FOR UNIT II

$$
\begin{gathered}
\text { HUS BAND } \\
\mathrm{BSI}_{1} \cdot \mathrm{BSI}_{2} \quad \mathrm{BSI}_{3} \quad \mathrm{PTA}_{1} \quad \mathrm{PTA}_{2} \quad \mathrm{PTA}_{3}
\end{gathered}
$$

SSA

QUES TION

$\underline{\text { SSB }}$

AGREEMENT

TAIK

$\underline{\mathrm{SSC}}$

AGREEIENT

QUES TION
QUES TION

6

$\varnothing$

20

3

$\varnothing$

1

$\varnothing$

$\varnothing$

$\varnothing$

$\varnothing$

$\varnothing$

$\varnothing$

$\varnothing$

2

1

WIFE

$\begin{array}{llllll}\mathrm{BSI}_{1} & \mathrm{BSI}_{2} & \mathrm{BSI}_{3} & \mathrm{PTA}_{1} & \mathrm{PTA}_{2} & \mathrm{PTA}_{3}\end{array}$

$\underline{\text { SSA }}$

AGREEIENT

TAIK

$\underline{\text { SSC }}$

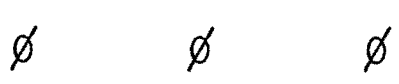

$5 \varnothing$

$\varnothing$

73

3

3

3

82

AGREENENT

$1 \varnothing$

1

1

2

4 
under SSB did not change in the desired direction following intervention (it remained essentially the same). Attending increased during SSB and SSC, Agreement increased during SSC, and Disagreement decreased during SSB and SSC (aII changes significant at the $p<.05$ level).

The wife's Agreement increased during SSA and Disagreement decreased during SSC, both significant at the $p<.05$ level. Disagreement showed a decreasing trend $(p<.1)$ under SSA.

The Talk Ratio of this U increased from .37 during BSI to . 55 during PTA, showing an increase in talking reciprocity。

The target behaviors which showed acceptable levels during all PTAs were the wife's Disagreement and the husband's Disagreement. All other behaviors showed less consistent improvement, but all met criteria at least once during PTA (see Table III).

Unit IV

The husband's target behaviors were Question, Agreement, and Attending; the wife's target behaviors were Agreement and Question. All except the wife's Question were shaped to increase in rate.

The husband's Question showed an increasing trend during.SSB $(p<.1)$ but showed no change during SSA. His duration of Attending increased both during SSB and $\mathrm{SSC}$, as did the rate of Agreement (all changes significant 
TABIE III

TARGET BEHAVIOR RATES FOR UNIT III

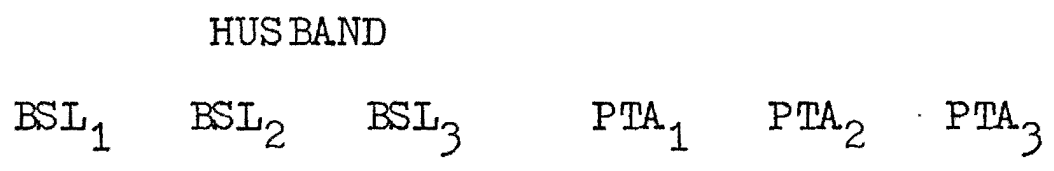

$\underline{\text { SSB }}$

ATTENDING

10

3

5

141

$61 \quad 176$

AGREENENT

$\varnothing 2$

2

2

4

3

DISAGREEMENT

2

$3 \cdot 5$

$\varnothing$

1

$\underline{\mathrm{SSC}}$
ATTENDING
AGREEMENT
DISAGREEMENT

10

25

17

110

97

163

2

2

$\varnothing$

6

3

3

$5 \quad 3$

6

$\varnothing$

$\varnothing$

2

WIFE

$\begin{array}{llllll}\mathrm{BSI}_{1} & \mathrm{BSI}_{2} & \mathrm{BSI}_{3} & \mathrm{PTA}_{1} & \mathrm{PTA}_{2} & \mathrm{PTA}_{3}\end{array}$

SSA

$\begin{array}{lllllll}\text { AGREEIUENT } & 1 & 1 & \varnothing & 3 & 3 & 5 \\ \text { DISAGREEUENT } & 2 & 4 & 5 & 2 & 1 & \varnothing\end{array}$

SSC

DISAGREEVENT

$5 \quad 1 \quad 4$

$\varnothing \quad \varnothing \quad \varnothing$ 
at the $p<.05$ level).

The Talk Ratio remained essentially the same for this couple, with values of .78 for BSI and .76 for PTA.

The behaviors which consistently met criteria during all of the PTAS were the wife's Question under SSB and SSC, and Agreement under SSA. The husband's Question under SSA and SSC also met criteria during all of the PTAS. The husband's Attending under SSB was the only target behavior which did not meet criteria at once during the PTAS (see. Table IV).

\section{CONSOLIDATED RESULTS}

There were a total of 34 behavior-condition combinations shaped during this study. Of these, 27 changed in the desired direction, 7 showed no change from BSI to PTA, and 0 showed a change in opposition of the direction in which it was shaped.

of the 34 behaviors, 8 met criteria during all of the PTAS and 3 did not meet criteria during any of the PTAs.

Twelve.target behaviors were assessed during more than one condition. of these, 2 did not change under the condition in which it had been shaped; 2 changed in the condition in which they had been shaped but not under any other condition; and 6 changed in the desired direction under all of the conditions.

Correlations of observer data were computed for 
TABIE IV

TARGET BEHAVIORS FOR UNIT IV

$$
\begin{aligned}
& \text { HUS BAND } \\
& \mathrm{BSI}_{1} \quad \mathrm{BSI}_{2} \quad \mathrm{BSI}_{3} \quad \mathrm{PTA}_{1} \quad \mathrm{PTA}_{2} \quad \mathrm{PTA}_{3}
\end{aligned}
$$

$\underline{\text { SSA }}$

$$
\text { QUES TION }
$$

51

$\varnothing$

3

6

4

$\underline{\mathrm{SSB}}$

$\begin{array}{lrrrrrr}\text { ATTENDING } & 4 & 10 & 8 & 63 & 49 & 78 \\ \text { AGREENENT } & \varnothing & \varnothing & 1 & 2 & 6 & 3 \\ \text { QUESTION } & 1 & \varnothing & 2 & 4 & 2 & 7\end{array}$

$\underline{\mathrm{SSC}}$
ATTENDING
$\varnothing \quad 10$
$\varnothing$
$102 \quad 120 \quad 226$
AGREEIENT
$1 \varnothing$
14
3
4
WIFE
$\begin{array}{llllll}\mathrm{BSI}_{1} & \mathrm{BSI}_{2} & \mathrm{BSI}_{3} & \mathrm{PTA}_{1} & \mathrm{PTA}_{2} & \mathrm{PTA}_{3}\end{array}$

$\underline{\text { SSA }}$

A.GREENENT

$\begin{array}{rr}3 & \varnothing \\ 18 & 10\end{array}$

$\varnothing$

4

4

5

QUESTION

23

4

6

3

$\underline{\text { SSB }}$

QUESTION

35

29

53

8

$\underline{\text { SSC }}$

AGREENENT

$\varnothing 1$

34

3

QUESTION

$2 \quad 4 \quad 31$

2

33


specific behaviors to derive an estimate of interrater reliability. The wife's Agreement during SSC for Unit I yielded an $r=.99$; the wife's Talk under SSB of Unit II yielded an $r=.86$; for Unit III, the husband's Attending yielded an $r=.82$; and for Unit IV, the husband's Question during SSA, SSB, and SSC yielded an $r=.99$. These correlations were higher for the discrete behavior measures but declined for duration measures, which involved more complex definitions. These data reflect a small set of data and are given as estimates. They reflect the reliability between the two experienced, trained observers. 


\section{CHAPTER V}

\section{DISCUSSION}

\section{EVALUATION OF THE HYPOTHESES}

The basic purpose of this program was to demonstrate the use of the BITE in a clinical setting with marital units. This purpose has been accomplished, but the clinical feasibility of the BITE needs further consideration. The BITE, as it has been used in the past, was hidden from the person not wearing the BITE. In this program the marital partner was aware of the BITE and this did not disrupt the interaction. Rather, the Us discussed their marital problems freely and seemingly without distraction.

Communication with the subject should not suffer due to the nature of the BITE. In this study, subjects became familiar with and accustomed to the BITE after one or two sessions, and since the placement of remarks by the shaper usually was such as to cause minimal disruption, subjects did not have to listen to their partners and the $\underline{\underline{T}}$ at the same time.

It is concluded that the BITE is feasible for use in maxital therapy and that its use should be investigated further.

The second part of this hypothesis involves efficien- 
cy: (a) in terms of delivery of shaping information; and (b) in the effect (the behavior change) produced. On the first count it was obvious that the BITE is a superior method of shaping information delivery. Reinforcements, cues, and prompts could be given often and quickly with little interruption in the marital interaction. The BITE also allowed a wide variety of information to be transmitted which would not be true of a signalling system.

The relative efficiency of the BITE shaping program in producing behavior change in subjects and Us needs to be evaluated in a comparative controlled study which was beyond the scope of this study, but it is the next step in the program development.

The third hypothesis regarding specific behavior changes in the marital interaction has been confirmed. Selected target behaviors changed significantly in the desired direction in almost all of the behaviors. However such change was not significant in all cases, and not all target behaviors showed any changes which were detectable by the statistical analysis. To test whether criterion levels is essentially a test of the shaping target and whether it was reached. For some behaviors the rate rose during shaping only to fall adequately during PTA to show no significant change: This raises serious questions about behavioral intervention into marital interaction. The Talk Ratio was used to assess reciprocity in the 
talking duration. Three Us showed an increase in talk reciprocity while one showed a slight decrease. Two of the three Us who showed increases had Talk as a target behavior. It may be that shaping other behaviors does not directly change the talk reciprocity。

The subjects evaluated the program favorabiy. This is an important aspect of the first hypothesis, since the clinical feasibility of the program depends in part on the subjects' reaction to the BITE.

A behavioral approach often disappoints Us who expect dynamic techniques, and the BITE may be an element seemingly too irrelevant to the marital problems. This problem did not occur with the study population.

\section{LIMITATIONS OF THE STUDY}

The hypothesis evaluations must be viewed with caution since the number of Us who went through the program was small. Further difficulties in using the data for generalizations arise when it is considered that the observers who evaluated the behavior rates were familiar with the hypothesis. The positive subjective evaluations of the program may have been due to demand characteristics and/or they knew that the program was designed by the I. Reported interrater reliability for the discrete behaviors was high, reflecting agreement on the definitions by the observers. The correlations for duration measures are lower, reflect- 
ing the complex nature of the duration measure definitions.

\section{ISSUES FOR FUIURE RESEARCH}

As with many studies of an exploratory nature, this program opens new avenues of research. Certain effects of the program have not been evaluated. The intended effect of the program is to establish a positive interaction pattern preparatory for contingency contract negotiation. The effect of the present program on subsequent contingency contract negotiation needs to be investigated. While three Us reported generalization of some behaviors to the home, home observation remains beyond the reach of most behavioral studies.

A study of the parameters of BITE reinforcement needs to be conducted. Such parameters as scheduals as schedules, voice characteristics, modes of articulation, and the prestige of the therapist must be evaluated in order to know which qualities and quantities of the BITE are most effective in creating behavior changes.

An intriguing question is the matter of attribution of behavior change. Is the BITE credited with new positive behaviors, or should the marital partner be given the credit? What is the effect of such attribution on the change of interaction?

A normative study of marital interaction involving the Behavior Coding Guide is required to determine Iess 
speculative criteria.

A study of this program comparing distressed with non-distressed Us must be done. If a $\underline{U}$ is highly distressed, it may be preferable to refer them for crisis intervention rather than this program. The baseline sessions may cause frustration in these Us because no intervention is begun until the baselines have been completed. However, the baseline sessions are important and useful if for no other reason than they put the focus on the marital interaction instead of the individual's complaints.

Finally, it may be that using problem areas as discussion topics reinforces complaint behavior, as was the case with one of the Us in the present study. Only future research can reveal whether other kinds of discussion topics should be used, especially during the shaping program.

\section{PROGRAM DEVELOPMENT AND CONCLUSION}

In the spirit of the clinical-research approach, the results of the present study will be utilized to modify the procedures of this program. These modifications will later be subjected to further tests including a comparative study of the efficacy in changing behavior. Much further research is needed into the complex issue of marital interaction. 
REEERENCES

Azrin, N. H.; Master, B. M., \& Jones, R. Reciprocity counseling: A rapid learning-based procedure for marital counseling. Behavior Research and Therapy, $1973,11,365-382$.

Bandura, A. Principles of behavior modification. New York: Holt, Rinehart, \& Winston, 1969.

Bandura, A., \& Walters, R. H. Social learning and personality development. New York: Holt, Rinehart, \& Winston, 1963.

Bard, M. Extending psychology's impact through existing community institutions. American Psychologist, $1969,24,610-612$.

Bergin, A. E., \& Strupp, H. H. Changing frontiers in the science of psychotherapy. Chicago: AldineAtheron, 1972 .

Birchler, G. R., Weiss, R. I., \& Wampler, I. D. Dif-ferential patterns of social reinforcement as a function of degree of marital distress and level of intimacy. Paper presented at the meetings of the Western Psychological Association, Portland, Oregon, 1972.

Bradburn, N. M., \& Caplovitz, D. Reports on happiness. Chicago: Aldine Publishing Co., 1965. 
Christensen, H. T. Handbook of marriage and the family. Chicago: Rand McNally \& Co., 1964. Clement, P. W. Operant conditioning in group psychotherapy with children. Journal of School Therapy, $1968,38,271-278$.

Cone, J. D. Social desirability and marital happiness. Psychological Reports, 1967, 21, 770-772.

Eisler, R. M., Hersen, M., \& Agras, W. S. Effects of videotape and instructional feedback on nonverbal marital interaction: An analog study. Behavior Therapy, 1973, 4, 551-558.

Ellis, A., \& Harper, R. A. The marriage bed. New York: Tower Publications, Inc., 1961.

Ely, A. I., Guemey, B. G., Jr., \& Stovr, I. Efficacy of the training phase of conjugal therapy. Psychotherapy, Theory, Research and Practice, 1973, 10, 201-207.

Federal Bureau of Investigation. Crime in the United States: Uniform crime reports. Washington, D. C.: U. S. Government Printing Office, 1968. Feldman, $\mathrm{H}$. The effects of children on the family. In A. Michel (Ed.), Family issues of employed women in Europe and America. The Netherlands: 1971.

Ferreira, A. J., \& Winter, W. D. Family interaction and decision-making. Archives of General Psychiatry, 
$1965,13,214-223$.

Ferster, C. Essentials of a science of behavior. In

J. I. Nurnberger, C. Ferster, \& J. P. Brady (Eds.),

An introduction to the science of human behavior.

New York: Appleton-Century-Crofts, 1963.

Goldstein, $\mathbb{M}$. K. Behavior rate change in marriages:

Training wives to modify husbands behavior. Unpub-

lished doctoral dissertation, Cornell University, 1971.

Goldstein, M. K., \& Francis; B. Behavior modification of husbands by wives. Paper presented at the meeting of the National Council on Family Relations, Washington, D. C., October, 1969.

Greene, B. I., \& Solomon, A. P. Marital disharmony: concurrent psychoanalytic therapy of husband and wife by the same therapist. American Journal of Psychotherapy, $1963,17,443-456$.

Greenspoon, J. Verbal conditioning and clinical psychology. In A. J. Bachrach (Ed.), Experimental foundations of clinical psychology. New York: Basic Books, 1962.

Greenspoon. J. The reinforcement effect of two spoken sounds on the frequency of two responses. American Journal of Psychology, 1955, 68, 409-416.

Hanf, C. Modifying problem behaviors in mother-child interaction: Standardized laboratory situation. 
Paper presneted at the meetings of the Association of Behavioral Therapies, Olympia, Washington, 1968.

Hanf, C. A two-stage program for modifying maternal controlling during mother-child (M-C) interaction. Paper presented at the meetings of the western Psychological Association, Vancouver, B. C., 1969.

Hanf, C., \& Kling, J. Facilitating parent-child interaction: A two-stage training model. Unpublished manuscript, 1973.

Hawkins, J. Association between companionship, hostility, and marital satisfaction. Journal of Marriage and the Family, 1967, 30, 647-650.

Henderson, N. B. Married group therapy: A setting for reducing resistances. Psychological Reports, 1965, 16, $347-352$.

Hicks, M. W., \& Platt, M. Marital happiness and stability: A review of the research in the sixties. Journal of Marriage and the Family, 1970, 33, 553-574.

Homme, I., Csanzi, A., Gonzales, Mo, \& Rechs, J. How to use contingency contracting in the classroom. Champaign, Illinois: Research Press, 1970.

Hops, H., Patterson, G. R., \& Weiss, R. I. Marital interaction coding system (MICS). Unpublished manuscript, 1972.

Kenton, A. Some functions of gaze-direction in social interaction. Acta Psychologicia, 1967, 26, 22-63. 
Knox, $\because$. Marital happiness: A behavioral approach to counseling. Champaign, Illinois: Research Press; 1972 .

Krapfl, J. E., Bry, P., \& Nawas, M. Uses of the bug-inthe-ear in the modification of parent's behavior. In R. D. Rubin \& C. M. Franks (Eds.), Advances in behavior therapy, 1968

Iazarus, A. A. Behavior therapy and marriage counseling. Journal of the American Society of Psychosomatic Dentistry and Medicine, 1968, 15, 49-56.

Iederer, W. J., \& Jackson, D. D. The mirages of marriage. New York: Norton, 1968.

Iiberman, R. Behavioral approaches to family and couple therapy. American Journal of Orthopsychiatry, 1970, 40, $106-118$.

Iocke, H. J., \& Wallace, K. M. Short marital adjustment and prediction tests: Their reliability and validity. Narriage and Family Iiving, 1959, 21, $251-255$.

Mace, D., \& Mace, V. Niarriage: East and west. New York: Doubleday, 1960.

Martin, P. A., \& Bird, H. W. An approach to the psychotherapy of marriage partners: The stereoscopic technique. Psychiatry, 1953, 16, 123-127.

Mead, M. Sex and temperament in three primitive societies. New York: New American Library, 1939。 
Mead, M. Male and female. New York: New American Iibrary, 1949.

Olson, D. H. Narital and family therapy: Integrative review and critique. Journal of Marriage and the Family, 1970, 22, 501-538.

Orden, S. R., \& Bradburn; N. A. Dimensions of marriage happiness. American Journal of Sociology, 1968, 13., $7-5-731$.

Patterson, G. R., \& Cobb, J. A. A dyadic analysis of aggressive behaviors. In J. P. Hill (Ed.), Minnesota Symposia on Child Psychology. Vol. 5. Minniapolis: University of Minnesota Press, 1971.

Patterson, G. R., \& Hops, H. Coercion, a game for two: Intervention techniques for marital conflict. In R. E. Ulrich \& P. Mountjoy (Eds.), the experimental aralysis of social behavior. New York: AppletonCentury-Crofts, 1972.

Patterson, G. R., \& Reid, J. B. Reciprocity and coercion: Two facets of social systems. In C. C. Neuninger \& J. I. Michael (Eds.), Behavior modification in clinical psychology. New York: AppletonCentury-Crofts, 1970.

Patterson, G. R.. Weiss, R. I., \& Hops, H. Training of of marital skills: Some problems and concepts. In H. Leitenberg (Ed.), Handbook of behavior modification. New York: Appleton-Century-Crofts, 1974. 
Reese, E. P. The analysis of human operant behavior. Dubuque: William C. Brown, 1966.

Reid, J. B. Reciprocity and family interaction. Unpublished doctoral dissertation, University of oregon, 1967.

Satir, V. Family communication and conjoint family therapy. In B. N. Ard \& C. C. Ard (Eds.), Handbook of marriage counseling. Palo Alto: Science and Behavior Books, 1969.

Skinner, B. F. The behavior of organisms. New York: Applrton-Century-Crofts, 1938.

Skinner, B. F. Science and human behavior. New York: Macmillan, 1953.

Steinmetz, S. K., \& Strauss, M. A. Some myths about violence in the family. Paper presented at the meeting. of the American Sociologist Convention, Houston, Texas: 1971.

Stephens, W. N. The family in cross-cultural perspective. New York: Holt, Rinehart, \& Winston, 1957. Stuart, R. B. Token reinforcement in marital treatment. In R. Rubin \& C. M. Franks (Eds.), Advances in behavior therapy. New York: Academic Press, 1968. Stuart, R. B. Operant interpersonal treatment for marital discord. Journal of Consulting and Clinical Psychologg, 1969, 33, 675-682。

Stumphauzer, J.S. A low cost "bug-in-the-ear" sound 
system for modification of therapist, parent, and patient behavior. In C. M. Franks \& G. T. Wilson (Eds.), Annual review of behavior therapy, theory and practice. New York: Brunner/Mazel, Inc., 1973. Terman, L. M. Measuring and predicting marital success. In M. Fishbein \& R. J. R. Kennedy (Eds.), Modern marriage and family living. New York: Oxford University Press, 1957.

Tharp, R. B. Psychological patterning in marriage. Psychological Bulletin, 1963, 60, 97-117.

Tsoi-Hoshmand, I. The limits of quid pro quo in couple therapy. The Family Coordinator, 1975, 25, 51-54. Turner, A. J. Couple and group treatment of marital discord: An experiment. Unpublished manuscript, 1972. Vincent, J. P. Problem-solving in distressed and nondistressed married and stranger dyads. Unpublished doctoral dissertation, University of Oregon, 1972. Vincent, J. P., Weiss, R. I., \& Birchler, G. R. A behavioral analysis of problem-solving in distressed and non-distressed married and stranger dyads. Unpublished manuscript, 1974.

Wahler, R. G., Winkle, G. H., Peterson, R. F., \& Morrison, D. C. Mothers as behavior therapists for their own children. Behavior Research and Therapy, 1965, 2 , 113-124.

Walker, H., \& Buckley, N. R. Teacher attention to 
appropriate and inappropriate classroom behavior: An individual case study. Focus on Exceptional Children, 1973, 5, 5-11.

Weiss, R. I., Hops, H., \& Patterson, G. R. A framework for conceptualizaing marital conflict, a technology for altering it, some data for evaluating it. In I. A. Hamerlynck, I. C. Handy, \& E. J. Mash (Eds.), Behavior change: Methodology concepts and practice. Champaign: Research Press, 1973.

Welsh, R. S. A highly efficient method of parental counseling. Paper presented at the meetings of the Rocky Mountain Psychological Association, Denver, Colorado, 1966.

Wills, T. A., Weiss, R. I., \& Patterson, G. R. A behavioral analysis of the determinants of marital satis-. faction. Journal of Consulting and Clinical Psychologgi, 1974, 42, 802-811. 
APPENDIX I

AGREEIENT TO PARTICIPATE IN RESEARCH 
AGREENENT OF PARTICIPATION IN RESEARCH

This research project is about marital communication and it involves two subjects and two experimenters. "The research requires approximately 16 laboratory sessions distributed over eight weeks.

This is a clinical research program with various responsibilities and benefits possible. We thought it might be best to present these and to obtain the fully informed consent of all subjects involved.

For the subjects of the research, it will be important to be available for these eight weeks, to regularly be present at the appointed times, and to do assignments and bring them in when they are due. This will require work at home and the time involved will vary from couple to couple.

This is a clinical research program which, due to its nature, does not contain any secret procedures, deceptions, or manipulations which induce stress. Futhermore, all discussions and all clinical material produced by the couple is confidential and will not be released to anyone in a form which might make the subject's identifiable. For purposes of assessment and record-keeping the sessions will be taped, and the subjects give their consent for such taping herewith.

For the experimenters, this research will serve as a developmental step in the Marital Effectiveness Training 
Program. A report on these data will constitute part of the Masters degree for Cynthia Clay at Portland State University.

For the subjects, he hope for several benefits: first, they will have an opportunity to reflect on their communication; second, they will be given feedback on their communication behaviors, many of which they may have used automatically and may not have been aware of; and third, they will be trained in using many such behaviors towards the improvement of their interaction. The subjects are free to discontinue their participation in the project at any time. They are also free to request any information about the procedures at any time, and will be given honest answers.

Date:

Signitures:

(Subject)

(Subject)

Address:

Phone: 
APPENDIX II

CIAY-ARNOSCHT BEHAVIORAI INTERVIEW FORM 
CIAY-ARNOSCHT BEHAVIORAI INTERVIEW FORM

Interviewer: Date:

Interviewee: Spouse:

1. How does your day start? How does it go for you and your spouse in the morning and at breakfast time?

2. Do you spend weekdays with your spouse? Describe what you do together.

3. When you or your spouse comes home from work, what do the two of you do?

4. After supper how do you spend your evenings?

5. How does it go for the two of you when you visit friends?

6. When you have friends over?

7. How do the two of you get along with each other's relatives?

8. How do the two of you handle the disciplining and raising of your children?

9. How do the two of you handle household chores?

10. How do the two of you manage money in the household?

11. Do you show affection to each other by embracing, holding hands, kissing, etc.?

12. How do you handle the decision of whether or not you make love on a particular night?

13. How do you usually spend your weekends?

14. Are there any important areas which you would like to mention? 
A.PPENDIS III

CIAY-ARNOSCHT MARITAJ INVENTORY 


\section{CIAY-ARNOSCHT MARITAI INVENTORY}

Please answer the questions on this page at home when you have some time to yourself。 In your answers we would like you to be specific. For instance, instead of saying "My husband appreciates me," we would like you to write down what he does that shows that he appreciates you. For instance, "My husband kisses me when he comes home from work." Answer these questions alone and do not ask your spouse for advice!

Name:

Date:

1. Write down 5 things that your spouse does that please you. (Write down even small things; don't write things he doesn't do.)

2. Write down 5 things which you do that please your spouse.

3. Write down a "shopping list" of things that you want your spouse to do more often (limit 15).

4. Write down what interests and habbies the two of you share.

5. Write down 5 things which your spouse does that displease you.

6. Write down 5 things which you do that bother your spouse.

7. When you are happy with something your spouse does, how do you reward him/her? Describe in a few sentences what 
you do. (If you don't do anything, write that down.) 
APPENDIX IV

STANDARD INS TRUCTIONS 


\section{STANDARD INSTRUCTIONS}

Standard Situation $\underline{A}$

For the next ten minutes, (the husband) will talk about how he feels about the topic and tell this to (his wife). (Wife), it is your turn to do everything you can to show him that you understand his feelings, that you encourage him to tell them to you, and that you are "taking in" what he is saying. You can ask some questions to better understand what he is saying, but do not argue, disagree, or introduce new topics.

Standard Situation B

Now we reverse roles. For the next ten minutes, you, (wife) will talk about how you feel about the topic and tell it to your husband.

(Husband), it is your turn to show her that you understand her feelings, that you encourage her to tell them to you, and that you are "taking in" what she is saying. You can ask some questions to better understand what she is saying, but do not argue, disagree, or introduce new topics.

Standard Situation $\underline{C}$

For the next ten minutes, we would like to have you discuss the topic equally, both giving ideas, both of you trying to understand each other, and both of you offering courses of action. 
APPENDIX V

BEHAVIOR CODING GUIDE 
BEHAVIOR CODING GUIDE

\section{TAIK}

Definition: Accumulated time period during which subject emits any vocalization of at least 5 second duration, with pauses no longer than 5 seconds. Start recording: When vocalization has been emitted for 5 seconds and is being continued by the subject.

Keep recording: As long as the subject talks within any 5 second period.

Stop recording: When subject has stopped talking or has ceased to emit any vocalization for 5 seconds.

BOTH TAIK

Definition: Any period of time in which both subjects vocalize at the same time beyond 5 seconds, with neither. pausing for longer than 5 seconds.

Start recording: When both subjects have vocalized for 5 seconds and are continuing.

Keep recording: As long as both partners continue to vocalize with neither pausing for longer than 5 seconds. Stop recording: If any one or both subjects have ceased vocalizing for 5 seconds.

INTERRUPTION

Definition: Subject begins vocalization before the partner has stopped his for at least two seconds. 
QUES TION

Definition: A statement which by vocal intonation, grammatical configuration, and content, asks for information from the partner.

Do not record: If the question is rhetorical.

ATIENDING

Definition: Subject visually attends to the partner (which may roughly be gauged from gaze direction) and emits an attending cue at least once every 10 seconds. Start recording: When subject visually attends and emits the first cue.

Keep recording: As long as subject visually attends and emits an attending cue at least once in any 10 second period.

Stop recording: If subject fails to visually attend, fails to give a cue within 10 seconds, or continues verbal cue past 5 second limit.

DISAGREENENT

Definition: A statement indicating that the subject either feels differently about the matter than the partner or the subject thinks the partner is stating matters inaccurately or wrongly.

A.GREEMENT

Definition: Any utterance which conveys the subjects" agreement of the partner's statement and which takes 
longer than 5 seconds. 
APPENDIX VI

CRITERION IEVEIS 
CRITERION IEVETS

$\begin{array}{lll}\text { HUSBAND (SSA) } & \text { HUSBAND (SSB) } & \text { SSC } \\ \& \text { WIFE (SSB) } & \& \text { WIFE (SSA) }\end{array}$

AGREENENT

ATTENDING

BOTH TALK

DISAGREEMENT

INTERRUPTION

QUES TION

MALK

$$
\mathrm{NA}^{1}
$$

NA

$$
0-39
$$

NA

$3-14$

$4-9$

$121-549$
$4+$

$151-479$

$0-39$

$0-3$

$3-14$

$4 \cdot-9$

$51-299$
$4+$

$151-479$

$0-39$

$0-3$

$3-14$

$4-4$

$121-479$ 
A.PPENDIX VII

SHAPING PROCEDURE 
SHAPING PROCEDURE

1. Explanation of the significance and definition of the target behavior. In order to produce favorable cognitive sets towards imitation of target behaviors it is necessary to discuss the target behavior with the subject. For instance, if the target behavior is Attending, it may be useful to introduce the concept to the subject in this manner:

An important part of marriage is communication. You must understand your spouse if you are to get along with her. And, you must show her that you care and listen to her and that you understand her, because it is important for people to feel that they are being understood and listened to. One way of doing this is to be a good listener, to really carefully listen to what your spouse is saying and to show that you really understand her. How can you do that?

In subsequent verbalizations the subject is guided into specific elements of the attending behaviors. The $\underline{T}$ emphasizes the important points of Attending, which are eye contact, head nodding, brief supportive reactions to the partner's verbalizations, and an acknowledgement of recipt of the information (regardless of whether the subject agrees or disagrees with the partner). Other elements which are mentioned are that Attending also means the absence of disagreement statements, counterpoints, and rhetorical questions. These are mentioned only if excesses in these categories are present in the interaction.

2. Modeling sequerce. The I says:

Why don't we pretend that I an your spouse and I 


\begin{abstract}
am going to show you some of the specific things that we are talking about. Tell me about how you get along with your in-laws and I will show some of the things I can do to show you that I am actively listening
\end{abstract}

During the next few minutes the $\underline{T}$ displays a high rate of the attending behavior and occasionally explains what he is doing. He then asks the subject if he felt understood. The I then indicates that this is what we want him to do with him spouse, but that first he will be given a chance to rehearse.

3. Rehearsal sequence. During the next few minutes the I roleplays the subject's partner after instructing the subject to attend to him. This role-mode is briefly interrupted to reinforce the subject's Attending. Such reinforcements as "that's how to do it" and "that's very good" should be dispensed liberally, but the contingency should be preserved. A positive way to end the session is to say: "You are doing very well now. I think that you are ready to try it with your spouse. I'll be talking to you over the earphone in a minute." 